\title{
PRESENTACIÓN
}

\section{LAS FORMAS SOCIALES EN G. SIMMEL}

\section{Celso Sánchez Capdequí}

Universidad Pública de Navarra

En el ámbito de la ciencia sociológica, la obra de Georg Simmel (18581918) siempre ha aparecido muy controvertida. Incluso hoy sigue sin lograr el reconocimiento que merece por parte de la comunidad sociológica. Sin embargo, y esto es lo curioso, buena parte de sus escritos y trabajos de investigación estuvieron encaminados a hacer de la sociología una disciplina científica independiente, con un estatuto epistemológico propio e irreductible al de saberes afines como el de la psicología, la filosofía, etc ${ }^{1}$. A pesar de ello, su enorme sensibilidad para con el «fragmento» y «lo evanescente» de la vida moderna, su permanente búsqueda del detalle, sus múltiples perspectivas e intereses, su maestría para el ensayo donde expresaba el impulso antisistemático de su creatividad intelectual, así como una área de conocimiento sociológico aún sin deslindar, fueron factores que, en su conjunto, explican que dentro de la ortodoxia de la comunidad sociológica haya sido una figura con un reconocimiento intelectual escaso y tardío. No en vano, sólo a la edad de 56 años, es decir, cuatro antes de su muerte, consiguió la cátedra de Filosofía de la Universidad de Estrasburgo como colofón a una trayectoria intelectual orientada, mayormen-

1 Así lo pone de manifiesto David FrISBY, uno de los estudiosos más destacados de su obra y de su trayectoria intelectual. Ver su trabajo Georg Simmel, México, 1990, p. 22. Del mismo autor, ver también Sociological Impressionism. A Reassesment of Georg Simmel's Social Theory, Londres, 1981.

\section{Reis}


te, por el cuestionamiento de los esquemas idealistas y mecanicistas como marcos de explicación de una realidad social compleja, enraizada en los sustratos vitalistas de la existencia y provista de equipamientos institucionales siempre transitorios y sujetos al cambio imprevisible y a la renovación perpetua.

Los textos de G. Simmel que a continuación se presentan tienen como rasgo común el tratamiento de la vida como hecho fundamental, como realidad básica desde la que la sociedad es comprendida bajo una nueva luz: no tanto desde unas esencias y regularidades metahistóricas y generalizadoras como desde su permanente redefinición, su plasticidad, su maleabilidad, etc. La pretensión teórica de Simmel, antes de cualquier aproximación estrictamente sociológica, es la de dar cuenta de una metafísica de la vida donde poder contextualizar un visión de la realidad social cuyo funcionamiento y despliegue no se adapta a causas objetivas ni a leyes preestablecidas. Recular hasta el concepto de vida purgado de cualquier esquema de objetividad y carente de cualquier asomo de formalización a priori supone recuperar el sustrato fundacional e irreductible en que consiste la realidad social y desde el que, bajo el prisma de Simmel, ésta puede ser comprendida en toda su complejidad.

Como se verá a lo largo de los textos aquí presentados, el propio ser dinámico, mutable y fluente de la vida (social) incluye momentos de creatividad que culminan en la cristalización del flujo vital en formas o marcos simbólicos que estructuran la vida social (el componente institucional del que se desprende el carácter organizado de toda convivencia colectiva) y momentos de degeneración en los que la fuerza irreprimible del impulso renovador de la vida arrastra lo instituido (ya caduco), configurando formas socioculturales inéditas que vienen a responder a nuevas demandas epocales. Precisamente, este devenir perpetuo a cuyo paso se generan formas histórico-sociales al tiempo que se degeneran, remite a la trascendencia inmanente ínsita en el flujo vital y a su inextinguible potencial de renovación que es condición de posibilidad de todo proceso de formalización y que, paradójicamente, siempre sobrepasa todo límite cultural instituido y toda pretensión de agotar en la forma simbólica de cualquier sociedad la exuberancia y el derroche que el devenir de la vida conlleva.

La idea básica que aparece en los trabajos de Simmel ahora traducidos ( $L a$ trascendencia de la vida y El conflicto de la cultura moderna) no pretende infravalorar la dimensión objetiva, institucional y formal como constitutivos de toda sociedad (símbolos, representaciones, categorías, normas, etc.), ya que sólo como forma se encarna y se manifiesta la potencia (creadora) de la vida intersubjetiva. Más bien, aspira a desenterrar las condiciones de posibilidad que hacen factible la constitución de formas y de marcos objetivos de vida social en la historia. Pues bien, el hallazgo de las pesquisas sociológicas de Simmel no es otro que la vida en estado bruto, vida que conlleva un "plus» de trascendencia inmanente que la faculta para desdoblarse, sublimarse y dar lugar a transitorios estados de formalización en la historia en donde se fijan unos límites cosmovisionales y conceptuales definitorios de lo racional, lo normal, lo bello, lo justo, 
etcétera para una forma de vida humana (y en donde la fuerza renovadora de la vida parece estancarse y coagularse de manera pasajera). Esta idea se concreta, según Simmel, en el ejemplo de la experiencia humana, ya que ésta, por su natural inadaptación al mundo, se encuentra sedienta de normas, leyes, conceptos; en definitiva, de límites culturales o formas objetivas a cuyo través puede dotar de orientación y orden a su existencia y puede hacer frente a las contingencias que le asaltan de continuo.

La capacidad de la vida para autotrascenderse de manera permanente apunta a una potencia o fuerza que atraviesa, cruza y trasciende todos sus coágulos de sentido o formas socioculturales establecidas en la historia. Dicho de otro modo, la percepción de la realidad social desde la óptica de sus instancias posibilitantes, como son el derroche y el empuje de la vida, hace posible la comprensión de una idea sorprendente y difícilmente asimilable para nuestra sociedad moderna y para el trasfondo de la cultura occidental que se encuentra a su base: el hecho de que la forma, y por ende "el Ser, lo que es», no sea siempre y eternamente (idéntico), como mantiene la filosofía griega, sino que su realidad es transitoria, es decir, es creada y, a su vez, sufre los procesos de degeneración y muerte, lo cual supone, para Simmel, que lo verdaderamente eterno y continuo es no tanto el Ser estático cuanto el tiempo, el cambio, la transformación y la renovación perpetua de la vida que se sustancia en la multitud de formas objetivas que los grupos humanos se han dado a lo largo de la historia y que, sometidas al paso del tiempo, se suceden sin pretensión alguna de establecerse en el devenir de la vida con carácter definitivo.

En todo caso, conviene no recaer en el polo opuesto, esto es, en una visión de la realidad social que, a instancias del hecho fundacional, básico e irreductible que es la vida, infravalore las formas, los límites objetivos como algo menor y subsidiario en toda vida humana y social. El propio Simmel se encarga de aclarar este problema al afirmar que la vida, precisamente por su trascendencia inmanente y su capacidad de desdoblamiento, precisa para su recurrente configuración de vitalismo y formalizaciones objetivas, mito y razón, urdimbre y estructura. Ambos momentos hacen posible la realidad social en permanente estado de cambio y alteración: una ilusión (en los términos de Freud) que anima una forma social, que vivifica una autoimagen y un proyecto colectivo que una sociedad se da a sí misma y una forma en que se objetiva, a modo de entramado institucional organizado (símbolos, representaciones, tótems, ritos), la ilusión de fondo².

Las expresiones que maneja Simmel a lo largo del primer texto aquí expuesto para dar cuenta de estos dos momentos constitutivos de la vida social son las de más-vida y más-que-vida. La primera se refiere a la inextinguible

2 Ante determinadas tendencias de religiosidad mística carente de mediaciones o formas simbólicas que tienen lugar en la sociedad moderna, Simmel apunta la necesidad de esas formas simbólicas de mediación en todas las actividades humanas de cara a articular, ritualizar, apalabrar y reconducir críticamente las potencias anímico-vitales que las animan. 
corriente de vitalismo profundo que permite trascender, recreándolo, lo vivido tiempo atrás, que hace posible edificar nuevas y múltiples autoimágenes e ilusiones colectivas que vienen a responder a nuevas demandas de la realidad social renovada. La segunda mienta el elemento de objetividad necesario en toda vida social y en el que lo creado se formaliza, se transforma en cuerpo espiritual preñado de significado, adquiriendo consistencia propia bajo el formato de un edificio institucional estable y regulador de la acción humana.

En el reconocimiento de esos dos momentos constitutivos de la vida social asoma la tragedia como realidad ineludible de toda producción humana, ya que si algo define a las formas sociales es su fugacidad y transitoriedad, su sertiempo a cuyo paso tiene lugar el nacimiento y la muerte de toda manifestación vital. Precisamente, sobre esta idea de la desasosegante presencia de la muerte como la eterna acompañante de la vida, Simmel parece hacer recaer la inevitabilidad de la creatividad social y, por ende, de la emergencia de nuevas subjetividades, objetos y valores. Al decir de Hans Joas ${ }^{3}$, Simmel detecta en la muerte la certificación de la contingencia y la vulnerabilidad de todo valor social instituido, las oquedades de un mundo que necesita de la implicación e intervención del actor social para reconstituirse como orden valorizado. Es el hecho de la inevitabilidad de la muerte el que pone en evidencia la transitoriedad de toda producción cultural y, además, la ineludibilidad de su recurrente reconstrucción. Esta afirmación da paso al cuestionamiento de cualquier intento de sustancializar valores, sujetos y objetos, de hipostasiar sustancias que pretendan huir del paso del tiempo, de hablar de la verdad como si de una entelequia se tratara.

Sin embargo, el propio Simmel, en uno de sus escritos de más enjundia y reconocimiento, La tragedia de la cultura, no parece ser fiel al carácter trágico derivado de la metafísica de la vida (que propugna en uno de los artículos aquí traducidos). En La tragedia de la cultura, y siempre teniendo como referencia a la modernidad, atisba los efectos de una división del trabajo tan extrema que el individuo, además de no reconocerse en sus producciones caracterizadas por su carácter anónimo e inexpresivo, tampoco acierta a armonizar y asimilar el cúmulo excesivo de conocimientos elaborados por una cultura ávida de desarrollo científico y cognitivo. De esta forma, Simmel sostiene que nuestra sociedad adquiere preocupantes muestras de alienación evidenciadas en el creciente distanciamiento de la subjetividad social, deseosa de aprovechamiento de sus productos cognitivos, y una objetividad científica (y económica) que parece conducirse con una inercia racionalizadora unilateral, ciega y ajena a cualquier demanda de una subjetividad que busca reconciliarse con ella. La tesis de Simmel no parece dejar lugar a dudas: nuestra forma de vida encalla en una experiencia trágica caracterizada por el hecho de que su obra se le ha ido de las manos, por el hecho de que deja de reconocerse en su rostro objetivo y recibe de ella destellos cargados de inexpresividad. Aquí Simmel recuerda al pesimis-

${ }^{3}$ H. JOAS, Die Enstehung der Werte, Frankfurt am Main, 1997, p. 127. 
mo weberiano de las últimas páginas de La ética protestante y el espiritu del capitalismo, en las que la experiencia moderna parece definirse únicamente por la zozobra existencial y el ocaso de unas esperanzas religiosas absorbidas por el sistema económico al que dieron pie.

Sin embargo, Simmel, ajeno a la metafísica de la vida y a la presencia de la muerte en ésta, defiende un concepto de tragedia estrecho que parece detenerse en el momento de conflicto y alienación de una cultura como la moderna, es decir, no plasma su metafísica trágica en una teoría de la acción ya que los actores sociales parecen no poder intervenir en la recreación de una realidad que, devenida exterior a la acción, avanza con una inercia irrevocable que lesiona la capacidad de actuación e intervención del individuo moderno. Simmel renuncia, por tanto, a rescatar la dimensión rejuvenecedora de la vida, sus aspectos recreadores, la transitoriedad de toda forma social. Afirma que la creatividad cultural del hombre moderno, según sus propias palabras, "se desliza con las imperceptibles modulaciones de una lógica evolutiva puramente objetiva hacia lo caricaturesco: hasta una especialización separada de la vida, hasta la autocomplacencia de una técnica que ya no encuentra el camino de regreso a los sujetos ${ }^{4}$. En definitiva, Simmel olvida que la metafísica de la vida se define por el hecho de que lo que hay es tiempo y que, por tanto, además de recordar los aspectos de alienación presentes en nuestra cultura (como en toda producción humana), también conviene mentar la creatividad inherente a la vida social, una creatividad que, por momentos, Simmel parece indicar que en nuestra sociedad se ha desecado y que ha muerto con carácter definitivo, algo que parece incongruente con su metafísica de la vida. En el último capítulo de su libro Las ciencias de la cultura, el filósofo neokantiano Ernst Cassirer detecta este achatamiento que sufre el concepto de tragedia en Simmel, desprovisto de ese "decir sí» (a pesar del "no" que también forma parte de la vida) del que hablaba Nietzsche en relación al hombre trágico. En concreto, Cassirer recuerda a Simmel que, a pesar de la escisión producida en la modernidad entre sujeto y objeto, «no debemos fijarnos solamente en el hecho del conflicto, sino también en su superación, en esa peculiar "catarsis" que constantemente se opera. Por muchas que sean las fuerzas que, por una parte, se ven encadenadas, no deben perderse de vista, de otro lado, las fuerzas nuevas y vigorosas que se emancipan. Este encadenamiento y esta emancipación simultáneos se manifiesta en la lucha entre las diversas culturas, como se manifiesta también, con no menos fuerza, en aquella lucha que el individuo se ve obligado a sostener con la colectividad, que las grandes fuerzas individuales creadoras libran con las que tienden a estancar y, en cierto sentido, a eternizar el estado de cosas existente. Lo creador se halla en constante pugna con lo tradicional» ${ }^{5}$.

A pesar de la falta de sintonía entre el concepto de tragedia y una teoría de la acción que pudiera derivarse lógicamente de aquél, la aportación teórica de

${ }^{4}$ G. Simmel, Sobre la aventura, Barcelona, 1988, p. 230.

5 E. CAssirer, Las ciencias de la cultura, México, 1982, p. 170. 
Simmel, en concreto su (propuesta de) metafísica de la vida, es de suma importancia para el momento cultural de su época porque golpea en el corazón de una sociología adormecida por el predominio narcotizante de un positivismo plegado al anodino y aproblemático imperio de los hechos. Simmel hace reflotar el fluido que posibilita y socava toda forma social y recuerda que el momento de coagulación del torrente vital dentro de unas formas conceptuales, categoriales, perceptivas, etc., no pasa de ser algo transitorio ante la potencia y la exuberancia de una vida que aspira a manifestarse bajo múltiples configuraciones y ropajes, que trasciende toda forma y que desbarata cualquier atisbo de interrupción y petrificación definitivas. Esta idea es algo que no ha sido comprendido en toda su amplitud por parte del proyecto moderno ( $\mathrm{y}$ de su forma de vida concomitante) ya que éste ha privilegiado el momento de la forma sobre el de la fecundidad de lo in-forme, el momento de la objetividad sobre el fondo vitalista de la existencia. Como afirma Simmel en otro de sus escritos, la vida moderna ha privilegiado los medios sobre los fines ${ }^{6}$, ha conferido carácter de realidad inmutable al ropaje tecnoeconómico de su configuración institucional donde la conducta humana parece desplegarse con movimientos regulares, previsibles y monótonos, $\mathrm{y}$ ha olvidado el eterno fondo vital y su trascendencia inmanente del que la vida moderna (como cualquier otra forma social independientemente de su grado de desarrollo, evolución o diferenciación) es símbolo. La apuesta teórica de Simmel colisiona directamente contra las pretensiones de sus contemporáneos de reducir la vida social a los movimientos previsibles y regulares de sus miembros y de sus instituciones, ignorando el todo procesual y dinámico del que son manifestación y las honduras de la vida in-forme desde donde todo se crea, se transforma y se renueva bajo inéditas formas cuya existencia histórica no soporta la inexorable ley del paso del tiempo.

En todo caso, y para finalizar, el proyecto sociológico de Simmel pretende ubicar las formas históricas de las sociedades sobre el eterno flujo de la vida y sobre su discurrir circular que, al tiempo que las crea, también después las engulle, haciendo de la muerte principio de vida y regeneración ${ }^{7}$. Precisamente, la contradicción (vital no lógica) que anida en el devenir irreprimible de la vida es que su permanente rebasamiento, transformación y autoalteración bajo múltiples ropajes es constitutivo de su ser procesual y dinámico, de donde se deriva una idea de lo social cuyo devenir no responde a fines preestablecidos ni a estaciones de fin de trayecto (Comte, Hegel, Marx, etc.), ya que lo eterno no es el ser, sino la inextinguible fuerza arrolladora que brota de las honduras de una vida que no quiere dejar de ser. Esto hace inútil toda tentativa de buscar

${ }^{6}$ G. Simmel, Filosofía del dinero, Madrid, 1977, p. 609.

Esta idea se acerca más al pensamiento arcaico y premoderno donde la muerte y la vida forman parte del discurrir procesual, renovador y circular (no lineal, como en nuestra modernidad) de la realidad (no estática) en el que la muerte, al tiempo que cierra un ciclo vital, abre otro (en una relación dialéctica de cierres y aperturas sin fin). Esta visión que subyace al pensamiento de Simmel se aleja de la percepción que tiene la sociedad moderna (de fuerte impronta judeocristiana), donde la muerte supone parón y cierre definitivo del flujo vital. 
leyes, constantes y regularidades en el devenir histórico de las sociedades, ya que, más allá de la captación mecanicista de lo real, éstas enraizan su existencia en una totalidad dinámica, renovadora y trascendente que nada sabe de unas causas, finalidades y razones (a priori), y que más bien en ella se preconciben (a posteriori), se generan y, en última instancia, se convierten en simbolo de su trascendencia (inmanente). 